\title{
NATIONAL SCHEME TRACKS SALMONELLA
}

he National Salmonella Surveillance Scheme (NSSS) has operated since 1980 as a data collection scheme for information on enteric organisms including Salmonella, Shigella, Vibrio and Yersinia throughout Australia and has published and circulated data since 1987. The custodian laboratory for the scheme is the Microbiological Diagnostic Unit (MDU) at the University of Melbourne. MDU is the World Health Organisation-affiliated reference laboratory for $S$. typhi and S. paratyphi and undertakes national Salmonella. phage typing. Laboratories, both public and private, provide data to the scheme on isolations of enteric pathogens from human, veterinary, environmental and food sources.

Over recent years in NSW there has been an increasing tendency to eat more meals outside the home and to buy more processed foods. In addition, food manufacturing has become more centralised with a consequent increased potential for foodborne outbreaks to affect larger segments of the community. The costs of this illness can be immense, not only to the health system and the wider community in lost work days, but also in the loss of community confidence in industries linked to foodborne outbreaks.

Surveillance and identification of enteric organisms from various environments, animals and foods is critical to understand the epidemiology and therefore the prevention of foodborne illness. The information collected and published by NSSS on isolations of enteric organisms from food, environmental and veterinary sources from both within NSW and throughout Australia provides a valuable resource when investigating the epidemiology of foodborne illness.

\section{FUNDING}

The computerised database was initially established with a $\$ 10,000$ grant from the National Health and Medical Research Council (NHMRC) in 1979. NHMRC funding continued intermittently until 1990 when the council considered it could no longer provide money for the scheme which it regarded as a monitoring service rather than a public health research project. In 1990 the Australian Institute of Health and the Victorian Health Department provided grants to the scheme. In 1991, on the basis of submissions from the Advisory Committee of the Communicable Diseases Network-Australia (CDNA), the Australian Health Ministers' Advisory Council took over funding and agreed that NSSS would become the coordinating centre for the surveillance of enteric pathogens and would provide national commentary on behalf of the CDN-A.

\section{VALUE OF THE SCHEME TO NSW}

Salmonella serovars are often specific to particular environmental niches and food industries. Similarly, some Salmonella serovars have defined geographical boundaries and consequently Salmonella serovars isolated from particular foods vary from State to State. This differentiation provides useful markers for the investigation of outbreaks. A current investigation by Food Inspectors of an apparent rise in incidence of $S$. virchow has utilised data provided by NSSS which show the organism is a common human isolation in
Queensland but not in other States and is commonly isolated from beef, particularly beef from the Northern Territory. National data are useful where an outbreak is generalised due to the wide distribution of a contaminated food. NSSS provides quarterly and annual human and non-human reports which include phage typing of different serotypes of salmonellae. These data are a valuable resource which contributes to analysis of trends and comparisons of normal levels of incidence with those which are indicative of specific outbreaks.

Annual reports of human isolates published by the scheme include case rate data for Salmonella on a Stateby-State basis for Australia, isolations from blood, urine and unusual sites, typhoid and paratyphoid cases, Shigella infections, infections acquired overseas, suspected and confirmed outbreaks and the top 10 salmonellas and phage types of $S$. typhimurium. The 1991 Human Annual Report was published in August 1992. Annual non-human reports include the total nonhuman notifications on a State-by-State basis, animal isolates, food isolates, a summary of isolations from raw meats, meat products, imported foods, animal feedstuffs, eggs, milk, milk products and environmental isolates. The 1990 Non-Human Annual Report was published in November 1991.

The monitoring of pathogens isolated from imported foods may be of invaluable assistance in preventing the introduction of new pathogens such as Salmonella enteritidis phage type 4 (PT4) to Australia. The incidence of $S$. enteritidis PT4 in the United Kingdom increased more than eightfold between 1984 and 1989. In 1990 there was a 25 per cent rise in incidence, and between January and August 1990 the Public Health Laboratory Service, Division of Enteric Pathogens for England and Wales reported that about 50 per cent of Salmonella isolations were $S$. enteritidis PT4. Contamination of shell eggs with $S$. enteritidis has also been reported in other European countries and the United States.

Presently NSSS collects more accurate data on the incidence of Salmonella than that obtained by the NSW Health Department's notification system under Section 16 of the Public Health Act 1991. In 1991 Salmonella notifications to the Department totalled 1,274 whereas NSSS received 1,548 notifications.

Apart from publishing data, staff associated with the scheme have acted as a direct resource for information to State health authorities and microbiologists from medical, veterinary, food technology and water laboratories. Laboratory staff associated with the scheme are in a position to notice sudden increases in incidence of isolations of particular organisms more rapidly than other organisations. In November 1991 staff associated with the scheme notified the NSW Health Department of a sudden increase of S. typhimurium phage type 9 which appeared to be an outbreak. This apparent outbreak was subsequently investigated by the Department. Data from NSSS were used by Departmental staff to assess the significance and extent of the apparent outbreak. 
during the survey were found to be infected with Salmonella heidelberg. The investigation has led one major manufacturer to modify its cooking process for unfermented salami products.

Investigation of Salmonella notification system Delay between the collection of clinical specimens and notification to investigating officers was determined as a limiting factor in efficient investigation, both in determining whether a specific detailed investigation was required and in limiting the efficiency of normal procedures.

An analysis of the flow of data between the time of collection of clinical specimens and food inspectors receiving results showed an extremely complex flow of data with multiple handling. A meeting of staff from laboratories, public health units, Food Inspection Branch and the Epidemiology and Health Services Evaluation Branch to try to improve the flow of information achieved considerable success, with co-operation form all parties. Food inspection staff now collect notifications directly from the Institute of Clinical Pathology at Westmead Hospital and serotyping results are sent directly to Food Inspection staff pass the notifications on to other interested parties who do not require the information as urgently.

\section{DISCUSSION}

The results of the investigation were inconclusive as to the cause of an upsurge in the incidence of Salmonella typhimurium phage type 9 . It may have been possible for contaminated salami (or possibly cross-contamination from salami through equipment such as slicing machines to other smallgoods) to have been implicated in the transmission of Salmonella typhimurium phage type 9.

While the cause of this outbreak remains inconclusive, the investigation was extremely worthwhile. The greatest lesson was the importance of a timely and accurate notification system. The sensitivity and efficiency of the notification and investigation program have now been improved, ensuring that future outbreaks of food poisoning will be detected early, allowing a quick and more effective response in terms of identifying and remedying the cause.

Although few common food sources were identified during the investigation, those that were identified were investigated thoroughly and, as a result, a food production process of considerable public health concern was uncovered. The investigation of this production process has resulted in manufacturers changing their cooking processes and in this way the potential for future outbreaks of Salmonella food poisoning from this food source has been reduced.

The benefits obtained from the investigation were in part due to its co-operative, multidisciplinary approach.

Johanna Westbrook, Public Health Officer,

Epidemiology and Health Services Evaluation Branch.

Edward Kraa, Senior Food Inspector;

Food Inspection Branch.

Michael Levy, Manager, Infectious Diseases Section,

Epidemiology and Health Services Evaluation Branch.

\section{ALTERNATIVE SOURCES OF DATA}

The South Australian Institute of Medical and Veterinary Science's Australian Salmonella Reference Laboratory publishes a monthly report detailing cultures typed at the laboratory. The report contains Salmonella serotype and phage type isolations from human, veterinary and food sources. This laboratory works in collaboration with MDU and sends Salmonella isolations to MDU for phage typing. Although this report is a valuable resource, it is not a complete report of all national isolations; rather it is a report on cultures typed at that laboratory.

The Commonwealth Department of Health, Housing and Community Services' Communicable Diseases Intelligence ( $C D I$ ) contains data on the national incidence of Salmonellosis. The August 1992 CDI contained the 1991 Annual Report. These data are not specific as to Salmonella serotypes or phage typing and contain only human isolations.

No other national resources of data on isolations of enteric pathogens are available.

\section{CONCLUSION}

NSSS provides a valuable resource to the NSW Health Department for the surveillance and investigation of foodborne illness caused by enteric pathogens and continued funding is recommended.

\section{Ed Kraa}

Policy Analyst, Foodborne Diseases Surveillance Epidemiology and Health Services Evaluation Branch. Phil Bird

Food Inspector (Oyster Program), Hunter Area Health Service

\section{PUBLIC HEALTH EDITORIAL STAFF}

The Bulletin's editorial advisory panel is as follows: Dr Sue Morey, Chief Health Officer, Public Health Division, NSW Health Department; Professor Stephen Leeder, Director, Department of Community Medicine, Westmead Hospital; Professor Geoffrey Berry, Head, Department of Public Health, University of Sydney; Dr Christine Bennett, General Manager, Royal Hospital for Women; Dr Michael Frommer, Deputy Director, Epidemiology and Health Services Evaluation Branch, NSW Health Department; Ms Jane Hall, Director, Centre for Health Economics Research and Evaluation; and Mr Michael Ward, Manager, Health Promotion Unit. The editor is Dr George Rubin, Director, Epidemiology and Health Services Evaluation Branch, NSW Health Department.

The Bulletin aims to provide its readers with population health data and information to motivate effective public health action. Articles, news and comments should be 1,000 words or less in length and include the key points to be made in the first paragraph. Please submit items in hard copy and on diskette, preferably using WordPerfect 5.1 , to the editor, Public Health Bulletin, Locked Mail Bag 961, North Sydney 2059. Facsimile (02) 3919232. Design - Health Public Affairs Unit, NSW Health Department. Suggestions for improving the content and format of the Bulletin are most welcome. 